\title{
IoT Based Smart Cupboard Design
}

\section{Rancang Bangun Smart Cupboard Berbasis IoT}

\author{
Trio Atmojo ${ }^{1}$, Shazana Dhiya Ayuni ${ }^{2}$,Indah Sulistyowati ${ }^{3}$,Arief Wisaksono ${ }^{4}$ \\ \{trioa1998@gmail.com ${ }^{1}$, shazana@umsida.ac.id ${ }^{2}$, Indahsulistyowati@umsida.ac.id ${ }^{3}$, ariefwisaksono@umsida.ac.id ${ }^{4}$ \} \\ Program Studi Teknik Elektro Fakultas Sains dan Teknologi Universitas Muhammadiyah Sidoarjo
}

\begin{abstract}
During the rainy season, the clothes can dry for 1 day or more. Often times when on the way home from work or school it is trapped in rain so that the clothes used are little damp, because the clothes are still used for tomorrow so the clothes are not possible to wash and can dry overnight. easy to open or break into by anyone, given the habit of people used to storing valuables in the cupboard, an extra security system is needed. Then a IOT-Based Smart Cupboard Design is made which aims to improve the function of a conventional wardrobe to be multifunctional, which is equipped with a damp clothes dryer feature and is equipped with a Fingerprint sensor which can only be accessed by the owner to open the wardrobe. to be equipped with a Fingerprint, which functions as extra security in opening cabinets where valuables are usually found. Also equipped with a fan and heater incubator functions in drying damp clothes. This tool is equipped with an IoT which functions as an On Off control for the fan and an incubator heater in heating damp clothes.
\end{abstract}

Keywords - IoT; Arduino Uno; Immune; Fingerprint Sensor; Heater Fan Incubator

\begin{abstract}
Abstrak. Saat musim penghujan menjemur pakaian tidak bisa kering 1 hari bahkan lebih. Sangat sering saat di tengah jalan pulang dari kantor maupun di sekolah terjebak oleh hujan yang menjadikan pakaian yang dipakai menjadi lembab, karena pakaian itu masih digunakan untuk besok jadi pakaian itu tidak mungkin dicuci dan bisa kering dalam semalaman, juga seringkali lemari pakaian saat ini masih menggunakan pengunci manual yang mudah dibuka atau dibobol oleh siapa saja, mengingat kebiasaan orang-orang terbiasa menyimpan barang berharga dilemari maka diperlukannya sistem pengamanan ekstra. Maka dibuatlah sebuah Rancang Bangun Smart Cupboard Berbasis IoT yang bertujuan untuk meningkatkan fungsi Lemari konvensional menjadi multifungsi yaitu dilengkapi dengan fitur pengering baju lembab dan dilengkapi sensor Fingerprint yang hanya bisa di akses oleh pemilik untuk membuka lemari. guna dilengkapi dengan Fingerprint yaitu berfungsi sebagai pengamanan ekstra dalam membuka lemari yang dimana biasanya terdapat barang berharga. Serta dilengkapi sebuah kipas dan Heater inkubator Berfungsi dalam Pengeringan Baju yang lembab. Alat ini Dilengkapi Dengan IoT yang berfungsi sebagai kontrol On Off kipas dan Heater Inkubator dalam memanaskan pakaian yang lembab.
\end{abstract}

Kata kunci - IoT; Arduino Uno; Sensor Fingerprint; Fan Heater Inkubator

\section{PENDAHULUAN}

Dari era modern saat ini teknologi berkembang pesat. Sistem yang ada dari alat yang dulunya menggunakan cara lama kini sudah ada sebuah mikrokontroler kini bisa menjadi serba otomatis, bisa dilihat dalam banyak sekali peralatan elektronik yang ada pada kehidupan saat ini yang semakin serba menjadi otomatis, mulai dari pengaplikasian yang canggih serta lebih sederhana. Berbasiskan mikrokontroler dari peralatan pada elektronik yang mempunyai manfaat sangat luar biasa bila dikembangkan lagi di bidangnya oleh para ahli, Dalam hal ini terlihat dari maraknya penggunaan peralatan elektronik otomatis untuk membantu manusia dalam menjalankan pekerjaan sehari-hari [1]. Demikian sama hal dengan sebuah keamanan pada era modern ini masih banyak orang mengabaikan suatu keamanan pada suatu tempat penyimpanan seperti lemari dan brankas. Sehingga tempat penyimpanannya tidak terjaga dengan baik, walaupun suatu lemari dikunci dengan kunci yang biasa digunakan tetapi kemungkinannya lemari tersebut bisa dibuka dan bisa terjadinya pencurian[2][3].

Sistem keamanan saat ini sangatlah dibutuhkan. Salah satunya sistem keamanan pada pintu lemari pribadi yang rawan serta kemungkinan terjadinya pencurian pada barang berharga yang sering di simpan dalam lemari. Pada suatu lemari pribadi sekarang ini sangat diperlukan adanya sebuah keamanan[4].

agar bisa mengantisipasi bahaya nya pencurian yang dapat terjadi secara tak terduga dan tanpa 
Procedia of Engineering and Life Science Vol. 1. No. 2 Juni 2021

Seminar Nasional \& Call Paper Fakultas Sains dan Teknologi (SENASAINS 2 ${ }^{\text {nd }}$ )

Universitas Muhammadiyah Sidoarjo

sepengetahuan. Maka itu dibuatlah sebuah Rancang Bangun Smart Cupboard Berbasis IoT[5]. Tidak semua orang bisa membukanya karena dilengkapi dengan sistem keamanan berupa sensor sidik jari[6]. Tidak hanya itu, alat ini dirancang juga agar menjadi alat yang multifungsi dengan ditambahkan nya sebuah heater yang sudah tergabung dengan kipas DC 12v sebanyak 2 buah sebagai penghangat baju apabila saat menjemur pakaian tiba-tiba turun hujan tetapi pakaian dalam keadaan belum kering sempurna[7].

\section{METODE}

Pada penelitian ini menggunakan metode pengambilan dan pengolahan data yang dimana oleh data yang sudah diambil serta di uji akan dipergunakan untuk mengetahui perbandingan suhu serta dari kelembaban DHT11 serta dari keakurasiannya oleh sensor tersebut serta dilakukan monitoring secara jarak jauh dan pengiriman sebuah notifikasi jarak jauh menggunakan via IoT melalui aplikasi Blynk[8].

Berikut ialah langkah-langkah pengujian yang dilakukan :

1. Langkah yang pertama adalah dilakukan perancangan alat terlebih dahulu.

2. Langkah kedua ialah melakukan perancangan software berupa program menggunakan Arduino IDE.

3. Langkah ketiga membuat desain lemari untuk alat yang sudah dirangkai.

4. Langkah keempat memasukkan program pada minimum sistem NodeMCU v3.

5. Langkah kelima memasang semua alat yang sudah dirangkai ke lemari yang sudah dibuat.

6. Melakukan percobaan serta pengambilan data dari sensor fingerprint dengan cara menempelkan sidik jari yang sudah diverifikasi dan yang belum didaftarkan di fingerprint tersebut.

7. Langkah yang terakhir melakukan sebuah pengujian pengiriman notifikasi dan monitoring secara jarak jauh.

\section{HASIL DAN PEMBAHASAN}

\section{A. Pengujian sensor fingerprint}

Pengujian ini bertujuan untuk mengetahui fungsi dari fingerprint untuk membaca sidik jari yang sudah di inisialisaikan dapat terdeteksi atau tidak.

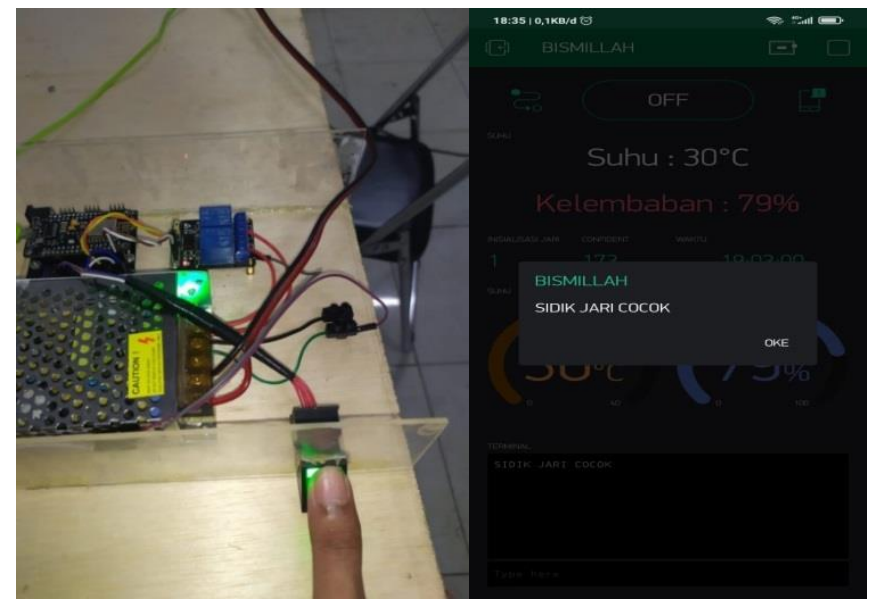

Gambar 1. pengujian fingerprint dengan sidik jari yang sudah teridentifikasi

Pengujian ini bertujuan untuk mengetahui fungsi dari fingerprint untuk membaca sidik jari yang sudah di inisialisaikan dapat terdeteksi atau tidak. 
Procedia of Engineering and Life Science Vol. 1. No. 2 Juni 2021

Seminar Nasional \& Call Paper Fakultas Sains dan Teknologi (SENASAINS 2nd)

Universitas Muhammadiyah Sidoarjo

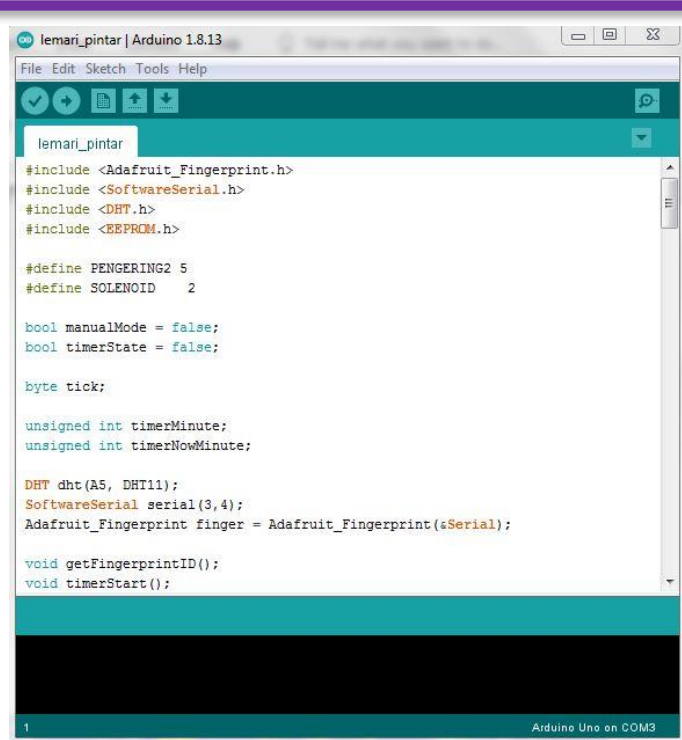

Gambar 2. Upload Program Berhasil

Dari Gambar 2 Di atas merupakan uji coba upload program ke NodeMCU V3. Pada percobaan yang sudah dilakukan hasilnya ialah program dapat di upload sehingga minimum sistem dapat menjalankan sensor fingerprint, DHT11, dan pengeringan.

Tabel 1. Pengujian Sensor Fingerprint dengan ibu jari sebelah kanan

\begin{tabular}{ccccc}
\hline Percobaan & Fingerprint & $\begin{array}{c}\text { Pengukuran } \\
(\mathrm{V})\end{array}$ & $\begin{array}{c}\mathrm{V} \\
(\mathrm{IN})\end{array}$ & Keterangan Alat \\
\hline 1 & 1 & 5,11 & 5.20 & $\begin{array}{c}\text { Lemari terbuka dan } \\
\text { notifikasi blynk } \\
\text { terkirim }\end{array}$ \\
\hline 2 & 1 & 5.11 & 5.20 & $\begin{array}{c}\text { Lemari terbuka dan } \\
\text { notifikasi blynk } \\
\text { terkirim }\end{array}$ \\
\hline 4 & 1 & 5.11 & 5.20 & $\begin{array}{c}\text { Lemari terbuka dan } \\
\text { notifikasi blynk } \\
\text { terkirim }\end{array}$ \\
\hline 5 & 1 & 5.11 & 5.20 & $\begin{array}{c}\text { Lemari terbuka dan } \\
\text { notifikasi blynk } \\
\text { terkirim }\end{array}$ \\
\hline $\begin{array}{l}\text { Rata-rata } \\
\text { Standar }\end{array}$ & 1 & 5.11 & 5.20 & $\begin{array}{c}\text { Lemari terbuka dan } \\
\text { notifikasi blynk } \\
\text { terkirim. }\end{array}$ \\
\hline & 0 & 5,11 & 5,20 & 0 \\
\hline
\end{tabular}

Dari Tabel 1 tertera nilai dari pengukuran, V (in). Pada pengujian tersebut mendapatkan pengukuran $5,11 \mathrm{v}$ dan $\mathrm{V}$ (in) 5,20v. Pengujian tersebut dilakukan sebanyak 5 kali percobaan dengan sidik jari yang sama yaitu menggunakan ibu jari sebelah kanan serta seluruh nya mendapatkan data pengujian berturut-turut dengan pengukuran $5,11 \mathrm{v}$ dan $\mathrm{V}$ (in) $5,20 \mathrm{v}$. Sehingga standart deviasi nya sangatlah rendah yaitu 0 yang menunjukkan bahwa alat berjalan dengan optimal. 
Procedia of Engineering and Life Science Vol. 1. No. 2 Juni 2021

Seminar Nasional \& Call Paper Fakultas Sains dan Teknologi (SENASAINS 2 ${ }^{\text {nd) }}$

Universitas Muhammadiyah Sidoarjo

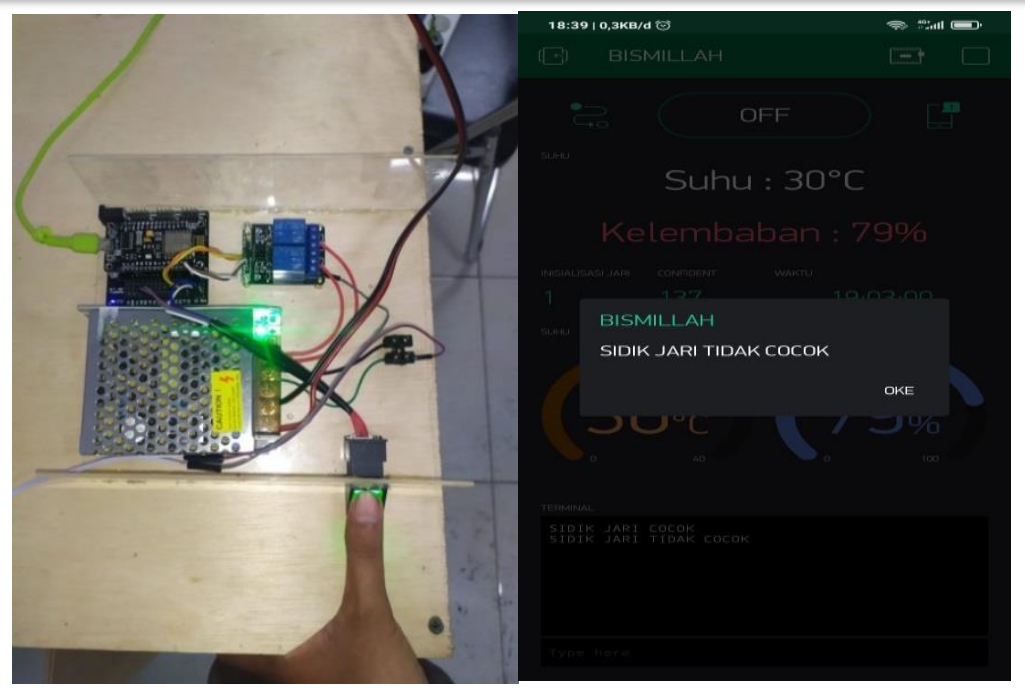

Gambar 3. Pengujian fingerprint dengan sidik jari yang belum di identifikasi

Dari Gambar 3 Pengujian ini bertujuan untuk mengetahui fungsi dari fingerprint untuk membaca sidik jari yang belum di verifikasi bisa terdeteksi atau tidak dan mendapatkan notifikasi sesuai sistem kerjanya.

Tabel 2. Pengujian Sensor Fingerprint dengan ibu jari sebelah kiri

\begin{tabular}{|c|c|c|c|c|}
\hline Percobaan & Fingerprint & $\begin{array}{c}\text { Pengukuran } \\
\text { (V) }\end{array}$ & $\begin{array}{c}\mathrm{V} \\
(\mathrm{IN})\end{array}$ & Keterangan Alat \\
\hline 1 & 0 & 5.20 & 5.20 & $\begin{array}{c}\text { Lemari tidak } \\
\text { terbuka dan } \\
\text { notifikasi blynk } \\
\text { terkirim }\end{array}$ \\
\hline 2 & 0 & 5.20 & 5.20 & $\begin{array}{c}\text { Lemari tidak } \\
\text { terbuka dan } \\
\text { notifikasi blynk } \\
\text { terkirim }\end{array}$ \\
\hline 3 & 0 & 5.20 & 5.20 & $\begin{array}{c}\text { Lemari tidak terbuka } \\
\text { dan notifikasi blynk } \\
\text { terkirim }\end{array}$ \\
\hline 4 & 0 & 5.20 & 5.20 & $\begin{array}{c}\text { Lemari tidak terbuka } \\
\text { dan notifikasi blynk } \\
\text { terkirim }\end{array}$ \\
\hline 5 & 0 & 5.20 & 5.20 & $\begin{array}{c}\text { Lemari tidak } \\
\text { terbuka dan } \\
\text { notifikasi blynk } \\
\text { terkirim. }\end{array}$ \\
\hline Rata-rata & 0 & 5.20 & 5,20 & \\
\hline $\begin{array}{l}\text { Standar } \\
\text { deviasi }\end{array}$ & 0 & 0 & 0 & \\
\hline
\end{tabular}

Dari tabel 2 tertera nilai dari pengukuran, V (in). Pada pengujian tersebut mendapatkan pengukuran 5,20v dan V (in) 5,20v. Pengujian tersebut dilakukan sebanyak 5 kali percobaan dengan sidik jari yaitu menggunakan ibu jari sebelah kiri serta seluruh nya mendapatkan data pengujian berturut-turut dengan pengukuran $5,20 \mathrm{v}$ dan $\mathrm{V}$ (in) $5,20 \mathrm{v}$. Sehingga standart deviasi nya juga sangatlah rendah yaitu 0 yang menunjukkan bahwa alat berjalan dengan optimal. 
Procedia of Engineering and Life Science Vol. 1. No. 2 Juni 2021

Seminar Nasional \& Call Paper Fakultas Sains dan Teknologi (SENASAINS 2nd)

Universitas Muhammadiyah Sidoarjo

\section{B. Pengujian pembacaan jarak dari IoT}

Pengujian dari jarak dilaksanakan untuk mengetahui sejauh mana jarak transfer data antara mikrokontroler NodeMCU V3 dengan smartphone.

Tabel 2. Hasil Pengujian NodeMCU V3 Sebagai Transfer Jarak

\begin{tabular}{|c|c|c|c|c|c|c|c|}
\hline \multirow[b]{2}{*}{ No } & \multirow[b]{2}{*}{ SMARTPHONE } & \multirow[b]{2}{*}{ POSISI PENGGUNA } & \multirow[b]{2}{*}{ JARAK } & \multicolumn{3}{|c|}{ PENGUIIAN } & \multirow[b]{2}{*}{ KETERANGAN } \\
\hline & & & & NOTIFIKASI & PENGERING & FINGERPRINT & \\
\hline \multirow[b]{2}{*}{1} & \multirow{2}{*}{$\begin{array}{c}\text { Iphone 6S RAM } \\
2 \mathrm{~GB} \\
\text { CPU } 2.2 \mathrm{GHz}\end{array}$} & DI DALAM & $1 \mathrm{~m}$ & 1 & 1 & 1 & \multirow{4}{*}{$\begin{array}{l}\text { Berhasil } \\
\text { Mengerim } \\
\text { Notifikasi }\end{array}$} \\
\hline & & DI LUAR & $14 \mathrm{Km}$ & 1 & 1 & 1 & \\
\hline \multicolumn{4}{|c|}{ RATA RATA } & 1 & 1 & 1 & \\
\hline \multicolumn{4}{|c|}{ STANDAR DEVIASI } & 0 & 0 & 0 & \\
\hline \multirow[b]{2}{*}{2} & \multirow[b]{2}{*}{$\begin{array}{c}\text { Samsung A21 S } \\
\text { Android } 10 \mathrm{RAM} \\
6 \mathrm{~GB} \\
\text { CPU } 2 \mathrm{GHz}\end{array}$} & DI DALAM & $1 \mathrm{~m}$ & 1 & 1 & 1 & \multirow{4}{*}{$\begin{array}{c}\text { Berhasil } \\
\text { Mengerim } \\
\text { Notifikasi }\end{array}$} \\
\hline & & DI LUAR & $4,2 \mathrm{Km}$ & 1 & 1 & 1 & \\
\hline \multicolumn{3}{|c|}{ RATA RATA } & & 1 & 1 & 1 & \\
\hline \multicolumn{3}{|c|}{ STANDAR DEVIASI } & & 0 & 0 & 0 & \\
\hline \multirow[b]{2}{*}{3} & \multirow{2}{*}{$\begin{array}{l}\text { Oppo A5 } \\
\text { Android } 10 \\
\text { RAM } 3 \mathrm{~GB} \\
\text { CPU } 1,8 \mathrm{GHz}\end{array}$} & DI DALAM & $1 \mathrm{~m}$ & 1 & 1 & 1 & \multirow{4}{*}{$\begin{array}{l}\text { Berhasil } \\
\text { Mengerim } \\
\text { Notifikasi }\end{array}$} \\
\hline & & DI LUAR & $27 \mathrm{Km}$ & 1 & 1 & 1 & \\
\hline \multicolumn{4}{|c|}{ RATA RATA } & 1 & 1 & 1 & \\
\hline \multicolumn{4}{|c|}{ STANDAR DEVIASI } & 0 & 0 & 0 & \\
\hline \multirow[b]{2}{*}{4} & \multirow{2}{*}{$\begin{array}{c}\text { Oppo A83 } \\
\text { Android } 7.1 .1 \\
\text { RAM 2GB } \\
\text { CPU } 2,5 \mathrm{GHz}\end{array}$} & DI DALAM & $1 \mathrm{~m}$ & 1 & 1 & 1 & \multirow{4}{*}{$\begin{array}{l}\text { Berhasil } \\
\text { Mengirim } \\
\text { Notifikasi }\end{array}$} \\
\hline & & DI LUAR & $5,1 \mathrm{Km}$ & 1 & 1 & 1 & \\
\hline \multicolumn{4}{|c|}{ RATARATA } & 1 & 1 & 1 & \\
\hline \multicolumn{4}{|c|}{ STANDAR DEVIASI } & 0 & 0 & 0 & \\
\hline
\end{tabular}

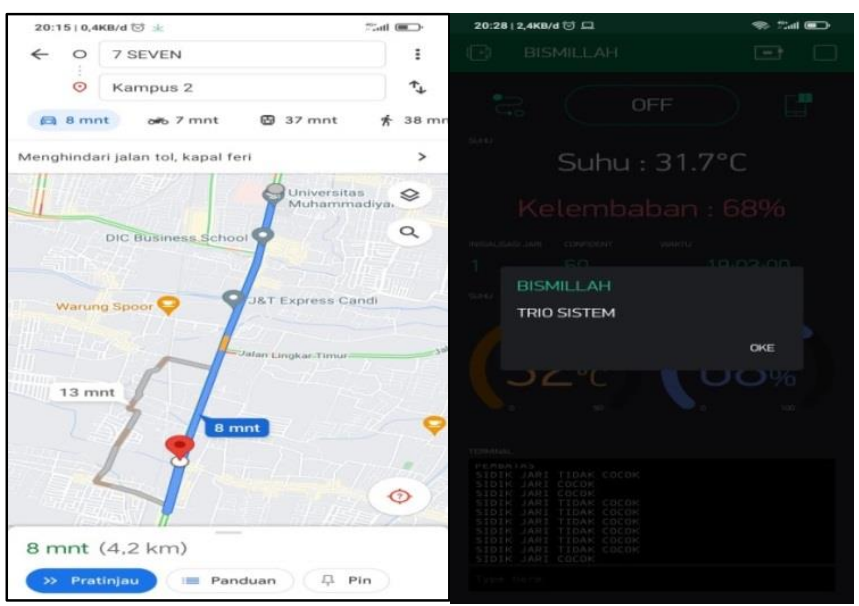

Gambar 4. Percobaan Blynk Pada Daerah Celep Sidoarjo

Pada gambar 4 merupakan percobaan Blynk yang diakses dari wilayah Celep Kec.Sidoarjo kabupaten Sidoarjo. Dari percobaan tersebut pada aplikasi blynk dapat di akses lewat Smartphone Samsung A21 S dengan provider IM3 guna untuk memonitoring secara langsung dari jarak yang jauh. 
Procedia of Engineering and Life Science Vol. 1. No. 2 Juni 2021

Seminar Nasional \& Call Paper Fakultas Sains dan Teknologi (SENASAINS 2nd)

Universitas Muhammadiyah Sidoarjo

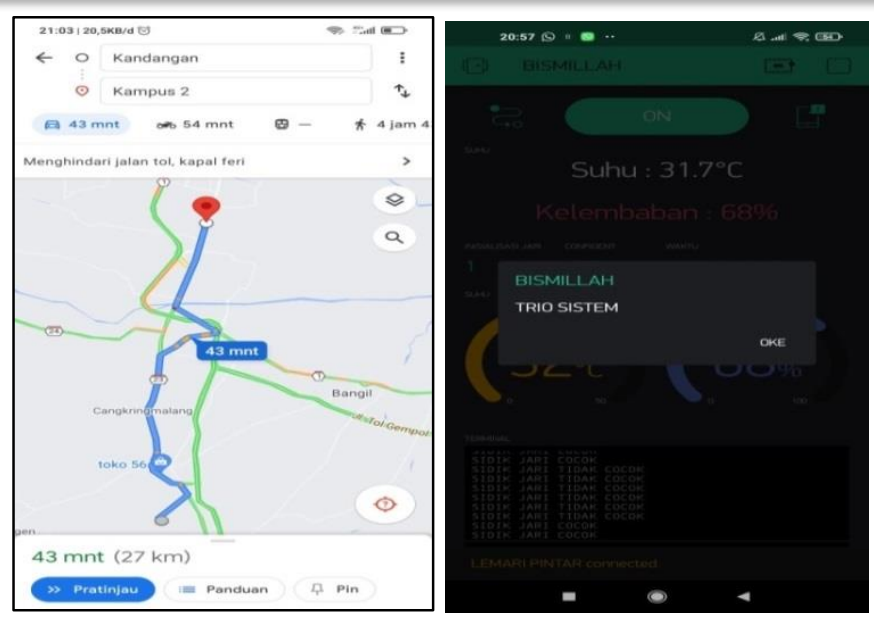

Gambar 5. Percobaan Blynk Daerah Kandangan Prigen

Pada gambar 5 merupakan percobaan Blynk yang diakses dari wilayah Kandangan Kec.Prigen kabupaten Pasuruan. Dari percobaan tersebut pada aplikasi blynk dapat di akses lewat Smartphone Oppo A5 dengan provider Tri guna untuk memonitoring secara langsung dari jarak yang jauh
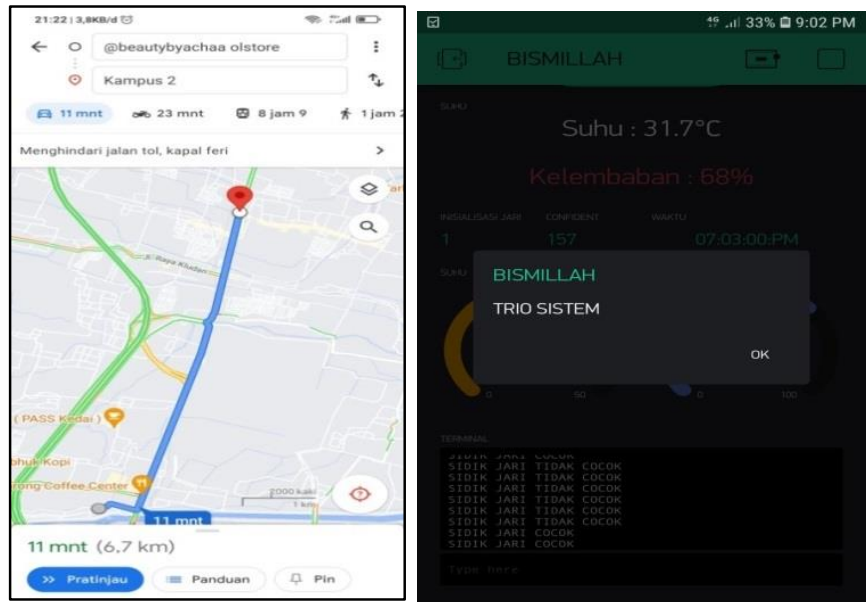

Gambar 6. Percobaan Blynk Daerah Porong Sidoarjo

Pada gambar 6 merupakan percobaan Blynk yang diakses dari wilayah Porong Kecamatan Porong kabupaten Sidoarjo. Dari percobaan tersebut pada aplikasi blynk dapat di akses lewat Smartphone Oppo A37f dengan provider Smartfreen guna untuk memonitoring secara langsung dari jarak yang jauh. 
Procedia of Engineering and Life Science Vol. 1. No. 2 Juni 2021

Seminar Nasional \& Call Paper Fakultas Sains dan Teknologi (SENASAINS 2nd)

Universitas Muhammadiyah Sidoarjo

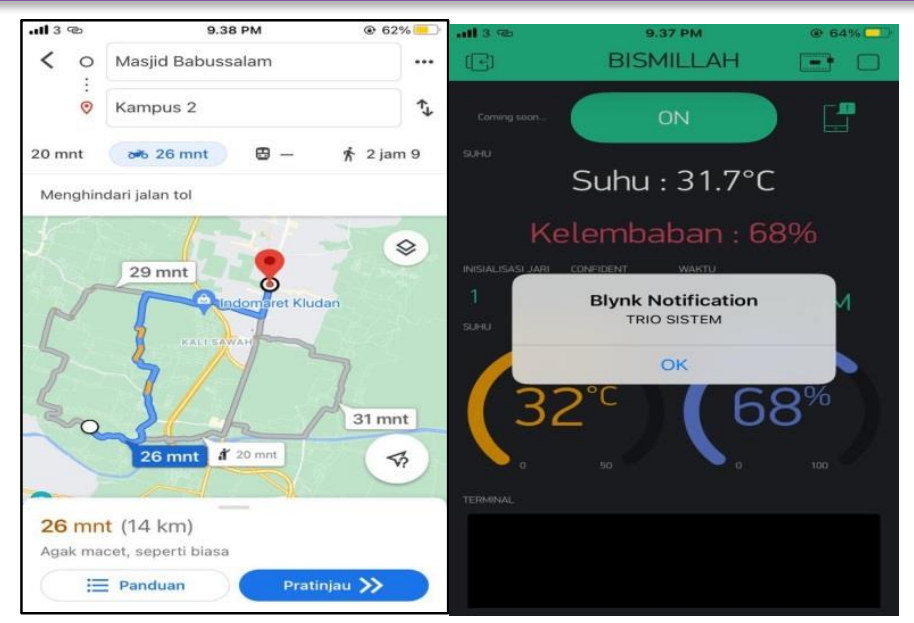

Gambar 7. Percobaan Blynk Daerah Krembung Sidoarjo

Pada Gambar 7 merupakan percobaan Blynk yang diakses dari wilayah Porong Kecamatan Porong kabupaten Sidoarjo. Dari percobaan tersebut pada aplikasi blynk dapat di akses lewat Smartphone Iphone 6S dengan provider tri guna untuk memonitoring secara langsung dari jarak yang jauh.

\section{KESIMPULAN}

Setelah dilakukannya proses pengujian serta pengambilan data dengan cara selama beberapa kali, maka telah didapatkan sebuah kesimpulan dari alat Rancang Bangun Smart Cupboard Berbasis IoT yang dapat disimpulkan untuk membuka pintu dari lemari pengering pakaian yaitu menggunakan sensor fingerprint dengan cara sidik jari yang telah sebelumnya di identifikasi ditempelkan pada sensor Fingerprint. Maka pintu dari lemari tersebut akan terbuka serta mengirim sebuah notifikasi pada Blynk dengan teks yang bertuliskan "SIDIK JARI COCOK". Apabila ada sidik jari belum di identifikasi tapi sidik jari tersebut tetap di tempelkan pada Fingerprint maka pintu lemari tidak akan terbuka dan akan mengirim notifikasi pada Blynk dengan bertuliskan "SIDIK JARI TIDAK COCOK". Pengontrolan suhu dan kelembaban serta waktu pada pengeringan baju melalui aplikasi Blynk. Untuk pembacaan suhu dan kelembaban dari mesin penering sendiri sudah bekerja secara optimal yaitu dengan rata-rata yang didapat pada suhu ruangan $36,46^{\circ} \mathrm{C}$ dan dengan kelembaban 75,20\% sedangkan komunikasi pada NodeMCU V3 yang menggunakan Smartphone melalui aplikasi Blynk dengan cara menguhubungkan internet bisa memantau dan mengontrol mesin pengering baju dengan jarak terjauh dari hasil pengujian adalah $20 \mathrm{~km}$.

\section{REFERENSI}

[1] S. Jari and B. Internet, "RANCANG BANGUN MINIATUR PENGAMAN PINTU OTOMATIS MENGGUNAKAN SIDIK JARI BERBASIS INTERNET of THINGS (IoT),” pp. 1-13, 2018.

[2] S. Pada, M. Baitul, and M. Pucu, “1,2,3),” vol. 1, no. 2, pp. 8-11, 2020.

[3] M. Atmega, E. Yuliza, and T. U. Kalsum, "Alat Keamanan Pintu Brankas Berbasis Sensor Sidik Jari Dan Passoword Digital Dengan Menggunakan,” vol. 11, no. 1, pp. 1-10, 2015.

[4] S. Sidik and J. Berbasis, "RANCANG BANGUN PENGAMAN PINTU PERSONAL ROOM MENGGUNAKAN SENSOR SIDIK JARI BERBASIS ARDUINO Hengky Yalandra 1 , Putra Jaya 2 2," vol. 7, no. 2, 2019.

[5] A. Wisaksono, M. I. Mauliana, and N. Ariyanti, "MONITORING DAN PENGENDALIAN PENGGUNAAN ENERGI PADA GEDUNG BERTINGKAT MENGGUNAKAN NODEMCU ESP 8266," pp. 178-185, 2019.

[6] P. Akhir, MAGNETIC DOOR LOCK MENGGUNAKAN KODE PENGAMAN BERBASIS AT MEGA 328. 2012.

[7] Sayid Ridho, Alat Penetas Telur Otomatis Berbasis Mikrokontroler. 2019.

[8] M. P. T. Sulistyanto, K. B. Pranata, A. N. Afandi, S. Sendari, and I. Sulistiyowati, "Monitoring electrical energy in electronic energy audits through internet of things technology," J. Phys. Conf. Ser., vol. 1402, no. 7, 2019, doi: 10.1088/1742-6596/1402/7/077067. 